\title{
The effects of corticosteroids on cognitive flexibility and decision-making in women with lupus
}

\begin{tabular}{|c|c|}
\hline Journal: & Lupus \\
\hline Manuscript ID & Draft \\
\hline Manuscript Type: & Paper \\
\hline Date Submitted by the Author: & $\mathrm{n} / \mathrm{a}$ \\
\hline Complete List of Authors: & $\begin{array}{l}\text { Montero-López, Eva; University of Granada, Department of Clinical } \\
\text { Psychology; } \\
\text { Santos-Ruiz, Ana; University of Alicante, Department of Health Psychology } \\
\text { Ortego-Centeno, Norberto; Hospital Universitario San Cecilio, Systemic } \\
\text { Autoimmune Disease Unit, Internal Medicine Service } \\
\text { Navarrete-Navarrete, Nuria; Hospital Universitario Virgen de las Nieves, } \\
\text { Systemic Autoimmune Disease Unit, Internal Medicine Service } \\
\text { Pérez-García, Miguel; University of Granada, Department of Clinical } \\
\text { Psychology; Mind, Brain and Behavior Research Center (CIMCYC), } \\
\text { University of Granada } \\
\text { Peralta-Ramírez, María Isabel; University of Granada, Department of } \\
\text { Clinical Psychology; Mind, Brain and Behavior Research Center (CIMCYC), } \\
\text { University of Granada }\end{array}$ \\
\hline Keyword: & $\begin{array}{l}\text { corticosteroids, executive function, flexibility, decision-making, systemic } \\
\text { lupus erythematosus (SLE) }\end{array}$ \\
\hline Abstract: & $\begin{array}{l}\text { The aim of this study was to investigate the possible effects of } \\
\text { corticosteroids in women with systemic lupus erythematosus (SLE) in two } \\
\text { processes of executive function: cognitive flexibility and decision-making. } \\
\text { To that end, we evaluated } 121 \text { women divided into three groups: } 50 \\
\text { healthy women, } 38 \text { women with SLE not receiving corticosteroid treatment } \\
\text { and } 33 \text { women with SLE receiving corticosteroid treatment. Cognitive } \\
\text { flexibility was measured with the Trail Making Tests A and B; decision- } \\
\text { making was measured with the Iowa Gambling Task. Additionally, } \\
\text { demographic (age and education level), clinical (SLEDAI, SDI and disease } \\
\text { duration) and psychological characteristics (stress vulnerability, perceived } \\
\text { stress and psychopathic symptomatology) were evaluated. The results } \\
\text { showed that both SLE groups displayed poorer decision-making than the } \\
\text { healthy women }(p=0.006) \text { and also that the SLE group receiving } \\
\text { corticosteroid treatment showed lower cognitive flexibility than the other } \\
\text { two groups }(p=0.030) \text {. Moreover, they showed the poorest scores on the } \\
\text { following SCL-90-R subscales: somatisation ( } p=0.005) \text {, obsessions and } \\
\text { compulsions }(p=0.045) \text {, depression ( } p=0.004), \text { hostility ( } p=0.013 \text { ), } \\
\text { phobic anxiety }(p=0.005) \text {, psychoticism ( } p=0.016) \text { and positive } \\
\text { symptom total }(p=0.001) \text {. Additionally, they were more vulnerable to } \\
\text { stress ( } p=0.000) \text {. These findings help to understand the effects of } \\
\text { corticosteroid treatment on cognitive flexibility and decision-making, in }\end{array}$ \\
\hline
\end{tabular}




\section{Page 1 of 33}

\section{LUPUS}

1

2

3

4

5

6

7

8

9

10

11

12

13

14

15

16

17

18

19

20

21

22

23

24

25

26

27

28

29

30

34

35

36

37

38

39

40

41

42

43

44

45

46

47

48

49

50

51

52

53

54

55

56

57

58

59

60

http://mc.manuscriptcentral.com/lupus 


\section{Title}

The effects of corticosteroids on cognitive flexibility and decision-making in women with lupus

\section{Author names and affiliations}

Eva Montero-López ${ }^{1}$, Ana Santos-Ruiz ${ }^{2}$, Norberto Ortego-Centeno ${ }^{3}$, Nuria NavarreteNavarrete $^{4}$, Miguel Pérez-García ${ }^{1,5}$ and María Isabel Peralta-Ramírez $z^{1,5}$

${ }^{1}$ Department of Clinical Psychology, University of Granada, Granada, Spain.

${ }^{2}$ Department of Health Psychology, Faculty of Health Sciences, University of Alicante, Alicante, Spain.

${ }^{3}$ Systemic Autoimmune Disease Unit, Internal Medicine Service, Hospital Clínico San Cecilio, Granada, Spain.

${ }^{4}$ Systemic Autoimmune Disease Unit, Internal Medicine Service, Hospital Universitario Virgen de las Nieves, Granada, Spain.

${ }^{5}$ Mind, Brain and Behavior Research Center (CIMCYC). Granada, Spain.

\section{Corresponding author}

Eva Montero-López, Ph.D. Student

Personality, Assessment and Psychological Treatment Department. Faculty of Psychology. University of Granada.

Campus de Cartuja, s/n

18071 Granada. Spain 
Telephone: $(+34) 660887695$

E-mail: evamonterolopez1983@gmail.com

1

2

3

4

5

7

8

9

10

11

12

13

14

15

16

17

18

19

20

21

22

23

24

25

26

27

28

29

30

31

32

33

34

35

36

37

38

39

40

41

42

43

44

45

46

47

48

49

50

51

52

53

54

55

56

57

58

59

60 


\begin{abstract}
The aim of this study was to investigate the possible effects of corticosteroids in women with systemic lupus erythematosus (SLE) in two processes of executive function: cognitive flexibility and decision-making. To that end, we evaluated 121 women divided into three groups: 50 healthy women, 38 women with SLE not receiving corticosteroid treatment and 33 women with SLE receiving corticosteroid treatment. Cognitive flexibility was measured with the Trail Making Tests A and B; decisionmaking was measured with the Iowa Gambling Task. Additionally, demographic (age and education level), clinical (SLEDAI, SDI and disease duration) and psychological characteristics (stress vulnerability, perceived stress and psychopathic symptomatology) were evaluated. The results showed that both SLE groups displayed poorer decisionmaking than the healthy women $(\mathrm{p}=0.006)$ and also that the SLE group receiving corticosteroid treatment showed lower cognitive flexibility than the other two groups ( $p$ $=0.030)$. Moreover, they showed the poorest scores on the following SCL-90-R subscales: somatisation $(\mathrm{p}=0.005)$, obsessions and compulsions $(\mathrm{p}=0.045)$, depression $(\mathrm{p}=0.004)$, hostility $(\mathrm{p}=0.013)$, phobic anxiety $(\mathrm{p}=0.005)$, psychoticism $(\mathrm{p}$ $=0.016)$ and positive symptom total $(\mathrm{p}=0.001)$. Additionally, they were more vulnerable to stress $(\mathrm{p}=0.000)$. These findings help to understand the effects of corticosteroid treatment on cognitive flexibility and decision-making, in addition to the disease-specific effects suffered by women with SLE.
\end{abstract}




\section{Keywords}

Corticosteroids, executive function, flexibility, decision-making, systemic lupus erythematosus (SLE)

\section{Introduction}

Patients with systemic lupus erythematosus (SLE) show a diverse symptomatology that manifests on both organic and neuropsychiatric levels. Its prevalence is slightly below $1: 1000$ in women and is tenfold lower in men. ${ }^{1-3}$

The decision to treat SLE with corticosteroids depends on the symptomatology, activity and severity of the disease. However, while corticosteroid treatment is indispensible for controlling the disease in some cases, it does produce adverse effects, some of which can lead to major organ damage. ${ }^{1,4,5}$

The adverse effects of corticosteroid treatment and organ damage in SLE patients have been broadly studied and reviewed and reveal major implications. ${ }^{5-7} \mathrm{~A}$ few of the most characteristic side effects are adrenal damage (which affects the thyroid), cardiovascular damage (hypertension or myocardial infarction), bone fractures, infections, cataracts, mood swings and sleep disorders.

The possible cognitive effects of corticosteroid use have also been studied. The majority of these studies have found no association between corticosteroid use and 
cognitive deficits in SLE patients. ${ }^{8-14}$ To the best of our knowledge, only one study has identified corticosteroid use as a factor associated with cognitive impairment in SLE. This study followed SLE patients for three years, and made evaluations every four months. These evaluations included standard medical history, physical examinations and cognitive testing. The results show that prednisone use was a factor associated with decreased cognitive function in SLE patients, as well as the presence of positive antiphospholipid antibodies, diabetes, increased depression and a lower education level. A few of the processes measured by Automated Neuropsychological Assessment Metrics (ANAM) were working memory, attention, non-verbal memory and visuospatial perception. ${ }^{15}$

Possible cognitive impairment in SLE patients has also been studied and associated with other variables linked to the disease itself or to the patients' psychological condition. The majority of these studies did not find any association between cognitive impairment and clinical characteristics such as disease activity, disease duration or neuropsychiatric manisfestations. ${ }^{10}$ An association was found, however, between psychological characteristics, such as stress, anxiety and depression, and cognitive impairment in SLE patients, namely with total attention accuracy, immediate visual memory, delayed visual memory and visual fluency, where greater stress indicated dysfunction in these processes. ${ }^{2,16-18}$ Moreover, research findings show that SLE patients with cognitive impairment had affected verbal and visuospatial 
memory and visuoconstructional abilities associated with neuropsychiatric manifestations. This cognitive impairment was not associated with disease activity, disease duration or corticosteroid use. ${ }^{10}$

Even though cognitive deficits and neuropsychiatric symptoms in SLE have been studied broadly, the possible effects of corticosteroid use on other aspects of executive function in SLE patients, such as flexibility and decision-making, have not. Various studies do show an association, however, between corticosteroid use and impairment in executive function (inhibition, working memory, shifting and planning, ${ }^{19}$ thus showing that corticosteroid use does have negative effects on working memory and the hippocampus, which in some cases leads to cerebral atrophy, regardless of dose and treatment duration or disease activity. ${ }^{20,21}$ Only one study has compared SLE patients receiving corticosteroid treatment with others not receiving corticosteroid treatment and healthy women. They found that the patients receiving corticosteroid treatment have greater cerebral atrophy than healthy women. Furthermore, SLE patients receiving corticosteroid treatment display more severe cerebral atrophy than patients without SLE who receive corticosteroid treatment, regardless of dose or treatment duration. $^{22}$

In spite of these approximations, the effects of corticosteroid treatment on executive function in SLE patients have not been studied. Therefore, the aim of our research has been to study if corticosteroid use has any effects on cognitive flexibility 
and decision-making in women with SLE when compared with healthy women. We hypothesise that women with SLE who receive corticosteroid treatment will display poorer decision-making and cognitive flexibility than women with SLE who do not receive corticosteroid treatment and healthy women.

\section{Material and methods}

\section{Patients}

One hundred twenty-one women participated in this study. They were divided in three groups. Group 1 (HW) was composed of 50 healthy women who were recruited via posters and Internet. Group 2 (SLE-CT) consisted of 38 women with SLE receiving corticosteroid treatment; group 3 (SLE-noCT) included 33 women with SLE not receiving corticosteroid treatment. The inclusion criteria for the women with SLE were to meet at least four ACR Classification Criteria for Diagnosis of SLE, to be over 18 years of age, to be literate and to not present any psychological disorders. Additionally, participants from the SLE-noCT group had to have not received corticosteroid treatment for at least one year previous to the study. All the participants with SLE were patients from the Systemic Autoimmune Disease Unit (Internal Medicine Service) at the University Hospital 'Virgen de las Nieves' and the Clinical Hospital 'San Cecilio' in Granada, Spain. The inclusion criteria for the healthy women comprising the control group were the same as those for the SLE groups, except that, additionally, they 
presented no mental or physical illnesses. This information was obtained through a brief semi-structured interview conducted when the women contacted us to participate in the study.

The main socio-demographic, clinical (SLEDAI, SDI and years with SLE) and treatment variables data were collected and recorded from the women with SLE. All the patients could at least read and write, and none of them presented any associated mental illnesses at the time of the study. All these patients and the healthy women gave their signed informed consent to take part in this study, which was approved by the ethics committee at our hospital and carried out in compliance with the Helsinki Declaration.

\section{Data collection}

All instruments used in the study were adapted versions validated in a Spanish population.

Trail Making Tests $A$ and $B$ (TMTA, TMTB). This is one of five stand-alone tests from the Delis-Kaplan Executive Function System (D-KEFS). ${ }^{24}$ Trail Making Tests A and B are timed tests of cognitive flexibility and visual motor integration that assess speed in processing information, attention and cognitive flexibility. The score obtained after dividing TMTB by TMTA produces the cognitive flexibility index and is the best execution indicator for the TMT. ${ }^{25-28}$ 
Iowa Gambling Task (IGT). This computerized task has been used to assess decisionmaking in a wide variety of studies. ${ }^{29}$ It simulates essential components of decisionmaking common to everyday life, and the assessment of rewarding and punishing events under conditions of uncertainty and risk. In the task, subjects must choose among four decks of cards. The task is composed of five blocks, each comprising twenty trials. Two decks provide a high and immediate gain but great future losses (long-term loss), while the other two decks provide lower immediate gains but a smaller future loss (long-term gain). The purpose of the task is to try to earn as much money as possible and to incur minimal losses when it is impossible to win. Initially, participants do not know these deck characteristics, but the program provides feedback about the consequences of each choice made by the participants. ${ }^{30}$

Stress Vulnerability Inventory (SVI). The SVI consists of 22 items and evaluates the individual's predisposition to be affected by perceived stress. ${ }^{31}$ The Spanish adaptation shows a Cronbach's alpha of $0.87 .^{32}$ As for convergent validity, the results show a significant positive correlation $(\mathrm{p}<0.01)$ with the following assessment scales: STAI-R, Beck Depression Inventory, Somatic Symptom Scale and Survey of Recent Life Experiences (SRLE).

Perceived Stress Scale (PSS). The PSS is a self-report scale used to evaluate perceived stress levels and the degree to which people find their lives unpredictable, uncontrollable or overwhelming (aspects that contribute to stress) ${ }^{33,34}$ It consists of 14 
items with five response alternatives. The highest score corresponds to the highest perceived stress level. The Spanish version of the PSS (14 items) has adequate reliability (internal consistency $=0.81$ and test-retest $=0.73$ ), concurrent validity and sensitivity. Here, we have considered those scores over 22 (i.e. the mean score for the Spanish population) as reflecting high levels of perceived stress. ${ }^{34}$

SCL-90-R Symptoms Inventory. ${ }^{35-36}$ We used this instrument to rule out potential psychopathology in the participants. This self-report questionnaire was developed to assess symptoms of psychopathology and it includes 90 items with five response alternatives (0-4) on a Likert scale. Subjects respond according to how they have felt within the past seven days, including the day the inventory is administered. The inventory is scored and interpreted according to nine main dimensions (somatisation, obsessive-compulsive symptoms, interpersonal sensitivity, depression, anxiety, hostility, phobic anxiety, paranoid ideation, and psychoticism) and three global indices of psychological distress (Global Severity Index (GSI), Positive Symptom Total (PS), and Positive Symptom Distress Index (PSDI)). In this study, we have analysed these last three global indices. This instrument is thought to have satisfactory reliability and validity. $^{36}$

The SLE Disease Activity Index (SLEDAI). The SLEDAI was used to assess lupus activity. ${ }^{37}$ It consists of 24 descriptors with pre-assigned severity weights. The total SLEDAI score can range from 0 (no activity) to 105 (maximum activity). The SLEDAI 
has been shown to be sensitive to changes in lupus activity measured by the treating physician.

Systemic Lupus International Collaborating Clinics/American College of Rheumatology (SLICC/ACR) Damage Index (SDI). The SDI is a physician-rated index that assesses cumulative organ damage due either to the disease or to complications of therapy. ${ }^{38}$ It includes 12 categories: ocular, neuropsychiatric, renal, pulmonary, cardiovascular, peripheral vascular, gastrointestinal, muscular-skeletal, skin, premature gonad failure, diabetes and cancer. Total scores range from 0 (no damage) to 48 (maximum damage).

\section{Procedure}

All the participants were scheduled individually at the Mind, Brain and Behaviour Research Centre at the University of Granada, Spain. Upon arrival to the laboratory they gave their signed informed consent. Their socio-demographic variables were then collected before carrying out the executive function tasks: the TMT (cognitive flexibility) and the IGT (decision-making). Subsequently, the psychological and stress tests were administered (SVI, SSP and SCL-90-R). Each session lasted approximately one and a half hours.

\section{Statistical analyses}


Results are presented as mean and standard deviation. To begin, ANOVAs were used for examining socio-demographic differences (age and education level) among the three groups (healthy women, SLE patients receiving corticosteroid treatment and SLE patients not receiving corticosteroid treatment). Also, Student's $t$-tests were used for comparing the clinical characteristics of SLEDAI, SDI and disease duration between both SLE groups. In addition, various ANOVAs were carried out for analysing differences in psychological variables (SVI, PSS and SCL-90-R) among all three groups. The independent variables were the three groups, i.e. healthy women, SLE patients receiving corticosteroid treatment and SLE patients not receiving corticosteroid treatment; the dependent variables were the scores on the SVI, PSS, and the SCL-90 subscales.

Finally, one-way ANOVAs were administered with the TMT (for cognitive flexibility) and the IGT (for decision-making) in order to check for any statistically significant differences in executive function between the three groups. Education level and SLEDAI were used as a covariate, as the groups were not evenly weighted in these variables, which can be closely tied to executive function. Differences were considered significant when $\mathrm{p}=0.05$. Additionally, correlation analyses were used to test the relationship between the psychological stress variables and executive function variables in each group, and correlation analyses were used to test the relationship between the SLEDAI and the cognitive performance variables. 


\section{Results \\ Participants' socio-demographic and clinical characteristics}

Socio-demographic and clinical data for the participants can be found in Table 1. The results showed statistically significant differences in education level and SLEDAI.

\section{TABLE 1}

\section{Psychological characteristics}

Table 2 shows psychological characteristics for the three groups. The results showed statistically significant differences in SVI $(p<0.001)$ among the three groups. The SLECT group is the most vulnerable to stress $(11.33 \pm 4.87)$, followed by SLE-noCT $(8.74$ $\pm 5.11)$ and finally by the healthy women $(5.96 \pm 3.77)$.

There were significant differences in the SCL-90 R results for the healthy women when compared with the SLE groups. Both SLE groups scored higher than the healthy women in the following sub-scales: somatisation $(p=0.005)$, obsessions and compulsions $(p=0.045)$, depression $(p=0.004)$, hostility $(p=0.013)$. In phobic anxiety $(p=0.005)$, psychoticism $(p=0.016)$ and positive symptom total $(p=0.001)$ the SLECT group scored higher than SLE-noCT and healthy women. 


\section{TABLE 2}

\section{Executive function}

The results showed statistically significant results on the IGT (decision-making) between both SLE groups and healthy women $(p=0.006)$. Healthy women $(4.08 \pm$ 20.38) scored higher on the decision-making task than SLE-CT $(-7.13 \pm 18.62)$ and SLE-noCT $(-9.00 \pm 23.35$ ) (Figure 1). As the negative value indicates, SLE patients show poorer decision-making regardless of corticosteroid use.

\section{FIGURE 1}

Figure 2 shows the decision-making scores from each of the five trials for the three groups.

\section{FIGURE 2}

Regarding cognitive flexibility, the results showed statistically significant differences on the TMT B/A (cognitive flexibility) among the three groups $(\mathrm{p}=0.030)$. SLE-CT $(2.57 \pm 0.90)$ showed poorer scores than SLE-noCT $(2.18 \pm 0.65)$ and healthy women $(2.06 \pm 0.60)$ (Figure 3).

\section{FIGURE 3}

Finally, no significant correlations were found among psychological stress, psychopathology, SLEAI and SDI or the executive function variables. 


\section{Discussion}

The aim of this research was to investigate if corticosteroid use is associated with impairment in two processes of executive function, i.e. cognitive flexibility and decision-making.

To this end, women with SLE receiving corticosteroid treatment, women with SLE not receiving corticosteroid treatment and healthy women were evaluated by testing cognitive flexibility and decision-making by using the Trail Making Test and the Iowa Gambling Task, respectively, while controlling for other variables such as the socio-demographic, clinical and psychological characteristics as well as disease-specific variables.

The results showed that women with SLE make poorer decisions than healthy women, regardless of corticosteroid use. This conduct, therefore, cannot be attributed to the medication. Notwithstanding, when comparing women with SLE receiving corticosteroid treatment with others who are not and with healthy women, a statistically significant difference does exist, namely that the first group scores the lowest. These results are in line with another study in which SLE patients scored higher than the control group on the TMTA and TMTB, thus displaying worse task execution. ${ }^{11}$ This also supports various studies reporting that corticosteroid use decreases both declarative and working memory, due to the atrophy it brings about in the hippocampus, ${ }^{41,42}$ and 
that this decrease is reversible by lowering the dose or stopping corticosteroid treatment altogether. $^{39,40}$

The results show lower decision-making scores for both SLE groups. Consequently, we can infer that it is the disease itself and its effects on the nervous system that may be affecting a poor task execution. On the other hand, factors such as disease activity could also be affecting these results. This parameter, however, did not correlate with decision-making or cognitive flexibility in our study. Therefore, decisionmaking cannot be attributed to disease activity. In this regard, our data coincide with those of other studies reporting that SLEDAI is not a predictive factor of cognitive deficit in SLE. ${ }^{43,44}$ It is related indirectly, however, as SLEDAI is a marker of lupus activity, which in some instances requires corticosteroids, a treatment component used for decreasing disease activity. Therefore, controversy remains regarding an association between cognitive impairment and markers of disease activity, ${ }^{11,45}$ as some studies find an association, ${ }^{11,46}$ while others, such as ours, do not. ${ }^{43,44,47}$

Regarding psychological conditions, there were differences in the majority of the stress and psychopathic symptoms variables between the women with SLE and the healthy women. These results can be expected however, because individuals suffering from a chronic disease experience pain, disability, major side effects from treatment and unpredictable aggravation of the disease, all of which can be extremely stressful and produce anxiety and depression. These results are consistent with other studies that 
report stress, anxiety and depression as possible factors that deteriorate symptomatology and quality of life in SLE patients. ${ }^{17,18,48,49}$

When considering the present study and its findings, there are a few limitations that need to be taken into account. This is the first study to analyse the effects of corticosteroids on executive function in women with SLE. In future studies more executive function parameters should be included with a similar sample, such as behaviour production, working memory, planning and inhibition, in order to assess if there are differences in the remaining executive function processes between women with SLE who receive corticosteroid treatment and others who do not receive corticosteroid treatment. Additionally, our groups did not share the same education levels, however, as this could be important, we did make sure to control for this factor. This variable was included as a co-variable in the TMT and IGT analyses among groups, as we are aware that some studies identify a lower education level as a factor associated with cognitive degeneration in SLE patients. ${ }^{10}$ At any rate, it is important to highlight the inherent difficulty in achieving equality in clinical populations.

In conclusion, the results from our study show that women with SLE display broader psychopathological symptoms, greater vulnerability to stress and poorer decision-making when compared with healthy women. Furthermore, as cognitive flexibility is lower in women with SLE who receive corticosteroid treatment than in healthy women and in women with SLE who do not receive corticosteroid treatment, 
the adverse effects of corticosteroid treatment on the cognitive flexibility of the first group should be considered. Whereas most studies have limited their research to the physical effects of corticosteroid treatment, the findings from our study are useful for studying the neuropsychological effects of corticosteroid treatment, as they provide more information regarding side effects, such as poorer decision-making and cognitive flexibility.

Poor decision-making and diminished cognitive flexibility entail a series of clinical implications for patients that concern doctors, as well as patients and their families, such as inadequate adherence to treatment plans or difficulties making the necessary changes to effectively deal with the disease. These findings are important for the specialised medical professionals caring for these patients, because a better understanding of these cognitive deficits can make a substantial advance towards understanding and even solving some of the different problems encountered on a daily basis.

\section{Funding}

This study is a part of a Doctoral Thesis and was supported by the I+D Project “PSI2010-15780” of the Spanish Ministry of Science and Innovation.

\section{Acknowledgements}




\begin{abstract}
We would like to thank the healthy women and patients with lupus who participated in this study.
\end{abstract}

\title{
Conflict of interest statement
}

The Spanish Ministry of Science and Innovation had no involvement in the study design, in the collection, analysis and interpretation of data, in the writing of the report, or in the decision to submit the paper for publication. 


\section{References}

1. Petri M, Bechtel B, Dennis G, et al. Burden of corticosteroid use in patients with systemic lupus erythematosus: results from a Delphi panel. Lupus 2014; 0: 1-8.

2. Santos-Ruiz, A. Mecanismos alterados de la respuesta al estrés en pacientes con lupus eritematoso sistémico. PhD Thesis, University of Granada, ES, 2011.

3. Aringer M, Hiepe F. Systemic lupus erythematosus. Z Rheumatol 2011; 70: 313-323.

4. Eder L, Urowitz MB, Gladman DD. Damage in lupus patients-what have we learned so far? Lupus 2013; 22: 1225-1231.

5. Ruiz-Irastorza G, Danza A, Khamashta M. Glucocorticoid use and abuse in SLE. Rheumatology 2012; 51: 1145-1153.

6. Sarnes E, Crofford L, Watson M, Dennis G, Kan H, Bass D. Incidence and US costs of corticosteroid-associated adverse events: a systematic literature review. Clin Ther 2011; 33: 1413-1432.

7. Ruiz-Arruza I, Ugarte A, Cabezas-Rodríguez I, Medina JA, Moran MA, RuizIrastorza G. Glucocorticoids and irreversible damage in patients with systemic lupus erythematosus. Rheumatology 2014; 53(8):1470-1476. 
8. Bhangle SD, Kramer N, Rosenstein ED. Corticosteroid-induced neuropsychiatric disorders: review and contrast with neuropsychiatric lupus. Rheuamtol Int 2013; 33: 1923-1932.

9. Sanna G, Bertolaccini ML, Khamashta MA. Neuropsychiatric involvement in systemic lupus erythematosus: current therapeutic approach. Curr Pharm Des 2008; 14 (13): 1261-1269.

10. Monastero R, Bettini P, Del Zotto E, et al. Prevalence and pattern of cognitive impairment in systemic lupus erythematosus patients with and without overt neuropsychiatric manifestations. J Neurol Sci 2001; 184: 33-39.

11. Nishimura K, Omori M, Katsumata Y, Sato E, Gono T, Kawaguchi Y, et al. Neurocognitive impairment in corticosteroid-naive patients with active systemic lupus erythematosus: a prospective study. The Journal of rheumatology, 2015; 42(3): 441448.

12. Maneeton B, Maneeton N, Louthrenoo W. Cognitive deficit in patients with systemic lupus erythematosus. Asian Pac J Allergy Immunol 2010; 28(1): 77-83.

13. Gladman DD, Urowitz MB, Slonim D, et al. Evaluation of predictive factors forneurocognitive dysfunction in patients with inactive systemic lupus erythematosus. J Rheumatol 2000; 27: 2367-2371. 
14. Kozora E, Arciniegas DB, Filley CM, et al. Cognitive and neurologic status in patients with systemic lupus erythematosus without major neuropsychiatric syndromes. Arthritis Rheum 2008; 59: 1639-1646.

15. McLaurin EY, Holliday SL, Williams P, et al. Predictors of cognitive dysfunction in patients with systemic lupus erythematosus. Neurology 2005; 64: 297-303.

16. Peralta-Ramírez MI, Coín-Mejías MA, Jiménez-Alonso J, et al. Stress as a predictor of cognitive functioning in lupus. Lupus 2006; 15: 858-864.

17. Peralta-Ramírez MI, Jiménez-Alonso J, Godoy-García JF, Pérez-García M. The effects of daily stress and stressful life events on the clinical symptomatology of patients with lupus erythematosus. Psychosom Med. 2004; 66: 788-794.

18. Peralta-Ramírez MI, Jiménez-Alonso J, Pérez-García M. Which stressors are responsible for the worsening in the clinical symptomatology of Lupus?. Health 2009; 1: 313-319.

19. Best JR, Miller PH, Jones LL. Executive Functions after Age 5: Changes and Correlates. Dev Rev. 2009; 29(3): 180-200.

20. Lupien SJ, Gillin CJ, Hauger RL. Working memory is more sensitive than declarative memory to the acute effects of corticosteroids: A dose-response study in humans. Behavioral Neuroscience 1999; 113 (3): 420-430. 
21. Cerqueira JJ, Pego JM, Taipa R, Bessa JM, Almeida OF, Sousa N. Morphological correlates of corticosteroid induced changes in prefrontal cortex dependent behaviors. Journal of Neuroscience 2005; 25(34): 7792-7800.

22. Zanardi VA, Magna LA, Costallat LT. Cerebral atrophy related to corticotherapy in systemic lupus erythematosus (SLE). Clin Rheumatol. 2001; 20(4):245-50.

23. Hochberg MC. Updating the American College of Rheumatology revised criteria for the classification of systemic lupus erythematosus (letter). Arthritis Rheum. 1997; 40 (9): 1725 .

24. Delis DC, Kaplan E, Kramer JH. Delis-Kaplan Executive Function System: Technical Manual. Harcourt Assessment Company, San Antonio, TX, 2001.

25. Ricker JH and Axelrod BN. Analysis of an oral paradigm for the Trail Making Test. Assessment 1994; 1: 47-52.

26. Lamberty GJ, Putnam SH, Chatel DM, Bieliauskas LA, Adams KM. Derived Trail Making Test indices: A preliminary report . Neuropsychiatry, Neuropsychology, and Behavioral Neurology 1994; 7: 230-234.

27. Arbuthnott K, Frank J. Trail Making Test, part B as a measure of executive control: Validation using a set-switching paradigm. Journal of Clinical and Experimental Neuropsychology 2000; 22: 518-528. 
28. Sánchez-Cubillo I, Periáñez JA, Adrover-Roig D, Rodríguez-Sánchez JM, RíosLago M, Tirapu J, et al. Construct validity of the Trail Making Test: Role of task switching, working memory, inhibition/interference control, and visuomotor abilities. Journal of the International Neuropsychological Society 2009; 15: 438-450.

29. Bechara A. The role of emotion in decision-making: evidence from neurological patients with orbitofrontal damage. Brain Cogn 2004; 55: 30-40.

30. Santos-Ruiz A, García-Ríos MC, Fernández-Sánchez JC, Pérez-García M, MuñozGarcía MA, Peralta-Ramírez MI. Can decision-making skills affect responses to psychological stress in the healthy women? Psychoendocrinology 2012; 37:19121921.

31. Beech HR, Burns LE, Scheefield BF. Tratamiento del estrés. Un enfoque comportamental. Madrid: Ed. Alambra, 1986.

32. Robles-Ortega H, Peralta-Ramírez MI, Navarrete-Navarrete N. Validación de la versión española del Inventario de Vulnerabilidad al Estrés de Beech, Burns y Scheffield. Avances en Psicología de la Salud. Granada: Ediciones Sider, 2006.

33. Cohen S, Kamarak T, Mermeistein R. A global measure of perceived stress. $J$ Health Soc Behav 1983; 24: 385-396. 
34. Remor E, Carrobles A. Versión española de la escala de estrés percibido (PPS-14): Estudio psicométrico en una muestra VIH+. Ansiedad y Estrés 2001; 7(2): 195-201.

35. Derogatis LR. Symptom checklist 90. Administration Scoring and Procedures Manual. National Computer Systems Inc: Minneapolis, 1994.

36. González de Rivera JL, De las Cuevas C. Versión española del cuestionario SCL 90-R. Universidad de la Laguna, Tenerife, 1988.

37. Bombardier C, Gladman DD, Urowitz MB, Caron D, Chang CH. The development and validation of the SLE Disease Activity Index (SLEDAI). Arthritis Rheum 1992; 35: 630-640.

38. Gladman D, Urowitz MB, Goldsmith C, Fortin P, Ginzler E, Gordon C. The reliability of the SLICC/ACR damage index in patients with SLE. Arthritis Rheum 1997; 40: 809-813.

39. Keenan PA, Jacobson, MW, Soleymani RM, Mayes MD, Yaldoo DT. The effect on memory of chronic prednisone treatment in patients with systemic disease. Neurology 1996; 47: 1396-1402.

40. Brown ES, Vera E, Frol AB, Woolston DJ, Johnson B. Effects of chronic prednisone therapy on mood and memory. Journal of affective disorders 2007; 99: 279-283. 
41. Brown ES. Effects of glucocorticoids on mood, memory, and the hippocampus. Annals of the New York Academy of Sciences 2009; 1179: 41-55.

\section{Appenzeller S, Carnevalle AD, Li LM, Costallat LT, Cendes F. Hippocampal} atrophy in systemic lupus erythematosus. Annals of the rheumatic diseases 2006; 65: $1585-1589$.

43. Kozora E, Thompson LL, West S G, Kotzin B L. Analysis of cognitive and psychological deficits in systemic lupus erythematosus patients without overt central nervous system disease. Arthritis \& Rheumatism 1996; 39: 2035-2045.

44. Carbotte RM, Denburg SD, Denburg JA. Cognitive dysfunction in systemic lupus erythematosus is independent of active disease .The Journal of rheumatology 1995; 22(5): 863-867.

45. Kozora, E., Hanly, J. G., Lapteva, L., \& Filley, C. M. (2008). Cognitive dysfunction in systemic lupus erythematosus: past, present, and future.Arthritis \& Rheumatism, 58(11), 3286-3298.

46. Conti F, Alessandri C, Perricone C, Scrivo R, Rezai S, Ceccarelli F, et al. Neurocognitive dysfunction in systemic lupus erythematosus: association with antiphospholipid antibodies, disease activity and chronic damage. PLoS One 2012; 7: e33824. 
47. Kozora E, Thompson LL, West SG, Kotzin BL. Analysis of cognitive and psychological deficits in systemic lupus erythematosus patients without overt central nervous system disease. Arthritis \& Rheumatism 1996; 39: 2035-2045.

48. Coín-Mejías MA, Peralta-Ramírez MI, Callejas-Rubio JL, Pérez-García M. Personal disorders and emotional variables in patients with lupus. Salud Mental 2007; 30 (2): $19-24$.

49. Peralta-Ramírez MI and Pérez-García M. The Effect of PsychoSocial Stress on Systemic Lupus Erythematosus: A Theoretical Review. In: Ulrich CM and Bellinger KA (eds) Systemic Lupus Erythematosus Research Developments. Nova Publisher. USA, 2007, pp.179-193. 
Table 1 Demographic and clinical characteristics in healthy women, SLE-noCT and SLE-CT

\begin{tabular}{|c|c|c|c|c|c|}
\hline SLEDAI & & $1.03(1.28)$ & $2.59(3.17)$ & $0.013^{*}$ & $\begin{array}{l}\text { SLE- } \\
\text { CT }>\text { SLE- } \\
\text { noCT }\end{array}$ \\
\hline SDI & - & $0.22(0.66)$ & $0.38(0.73)$ & 0.370 & - \\
\hline Disease duration, & - & $9.92(8.63)$ & $8.12(5.92)$ & 0.362 & - \\
\hline $\begin{array}{l}\text { years } \\
\text { Prednisone } \\
\text { dosage mg/day }\end{array}$ & - & - & $6.35(2.74)$ & - & - \\
\hline
\end{tabular}


Table 2 Psychological characteristics, in healthy women, and SLE-noCT and SLE-CT

\begin{tabular}{|c|c|c|c|c|c|}
\hline Variable & $\begin{array}{c}\text { HW } \\
(n=50)\end{array}$ & $\begin{array}{l}\text { SLE-noCT } \\
\quad(n=38)\end{array}$ & $\begin{array}{l}\text { SLE-CT } \\
\quad(n=33)\end{array}$ & $p$ & Post hoc \\
\hline $\begin{array}{l}\text { Perceived } \\
\text { Stress-Scale }\end{array}$ & $22.68(8.20)$ & $26.32(8.33)$ & $26.56(8.20)$ & 0.052 & \\
\hline $\begin{array}{l}\text { Stress } \\
\text { Vulnerability } \\
\text { Inventory }\end{array}$ & $5.96(3.77)$ & $8.74(5.11)$ & $11.33(4.87)$ & $0.001 * *$ & $\begin{array}{l}\text { SLE- } \\
\text { CT }>\text { SLE- } \\
\text { noCT }>\text { HW }\end{array}$ \\
\hline Symptom Che & $L-90-R$ & & & & \\
\hline Somatization & $52.80(9.31)$ & $58.24(8.01)$ & $59(10.11)$ & $0.005^{*}$ & $\begin{array}{l}\text { SLE- } \\
\text { CT=SLE- } \\
\text { noCT }>\text { HW }\end{array}$ \\
\hline $\begin{array}{l}\text { Obsessions } \\
\text { and } \\
\text { compulsions }\end{array}$ & $55.40(11.34)$ & $59.65(7.33)$ & $60.62(9.84)$ & $0.045^{*}$ & $\begin{array}{l}\text { SLE- } \\
\mathrm{CT}=\text { SLE- } \\
\text { noCT }>\text { HW }\end{array}$ \\
\hline $\begin{array}{l}\text { Interpersonal } \\
\text { sensitivity }\end{array}$ & $54.12(11.44)$ & $53.65(10.95)$ & $57.92(10.24)$ & 0.266 & \\
\hline Depression & $49.30(10.30)$ & $54.97(9.12)$ & $56.69(11.08)$ & $0.004 *$ & $\begin{array}{l}\text { SLE- } \\
\text { CT=SLE- } \\
\text { noCT }>\text { HW }\end{array}$ \\
\hline Anxiety & $52.24(9.72)$ & $55.46(8.27)$ & $57.38(10.10)$ & 0.060 & \\
\hline Hostility & $48.72(9.81)$ & $54.41(9.08)$ & $54.62(11.92)$ & $0.013 *$ & $\begin{array}{l}\text { SLE- } \\
\text { CT=SLE- } \\
\text { noCT }>\text { HW }\end{array}$ \\
\hline $\begin{array}{l}\text { Phobic } \\
\text { Anxiety }\end{array}$ & $43.20(11.62)$ & $45.43(12.86)$ & $53.12(12.82)$ & $0.005^{*}$ & $\begin{array}{l}\text { SLE- } \\
\text { CT }>\text { SLE- } \\
\text { noCT }=\text { HW }\end{array}$ \\
\hline
\end{tabular}




$$
\text { Paranoia }
$$

Psychoticism

48.72 (13.19)

$42.40(8.13)$

Global

Severity

Index

Positive

Symptom

Distress

Index

Positive

Symptom

Total

$53.72(12.91)$

$55.36(12.23)$

4
$52.86(11.97)$

$53.73(11.07)$

$60.70(9.18)$

$59.85(10.31) \quad 0.055$

43.57 (3.54)

$45.12(5.65)$

0.214

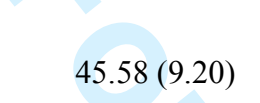

$48.92(7.73)$

$53.62(10.07) \quad 0.001 * *$
CT $>$ SLE-

noCT $=\mathrm{HW}$

\footnotetext{
Data are expressed as mean (S.D.) ${ }^{* *} \cdot \mathrm{p} \leq 0.01 .{ }^{*} \cdot \mathrm{p} \leq 0.05$
} 


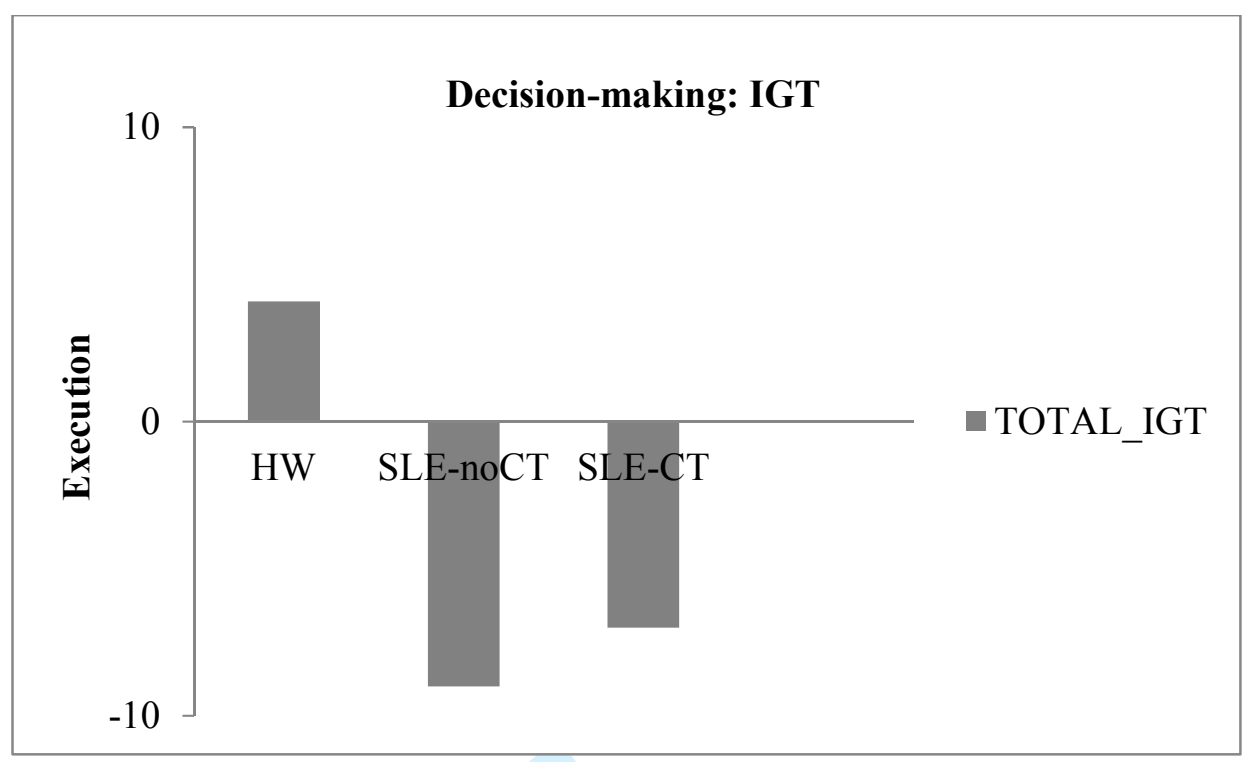

Figure 1 Making decision total in healthy women, and SLE-noCT and SLE-CT 


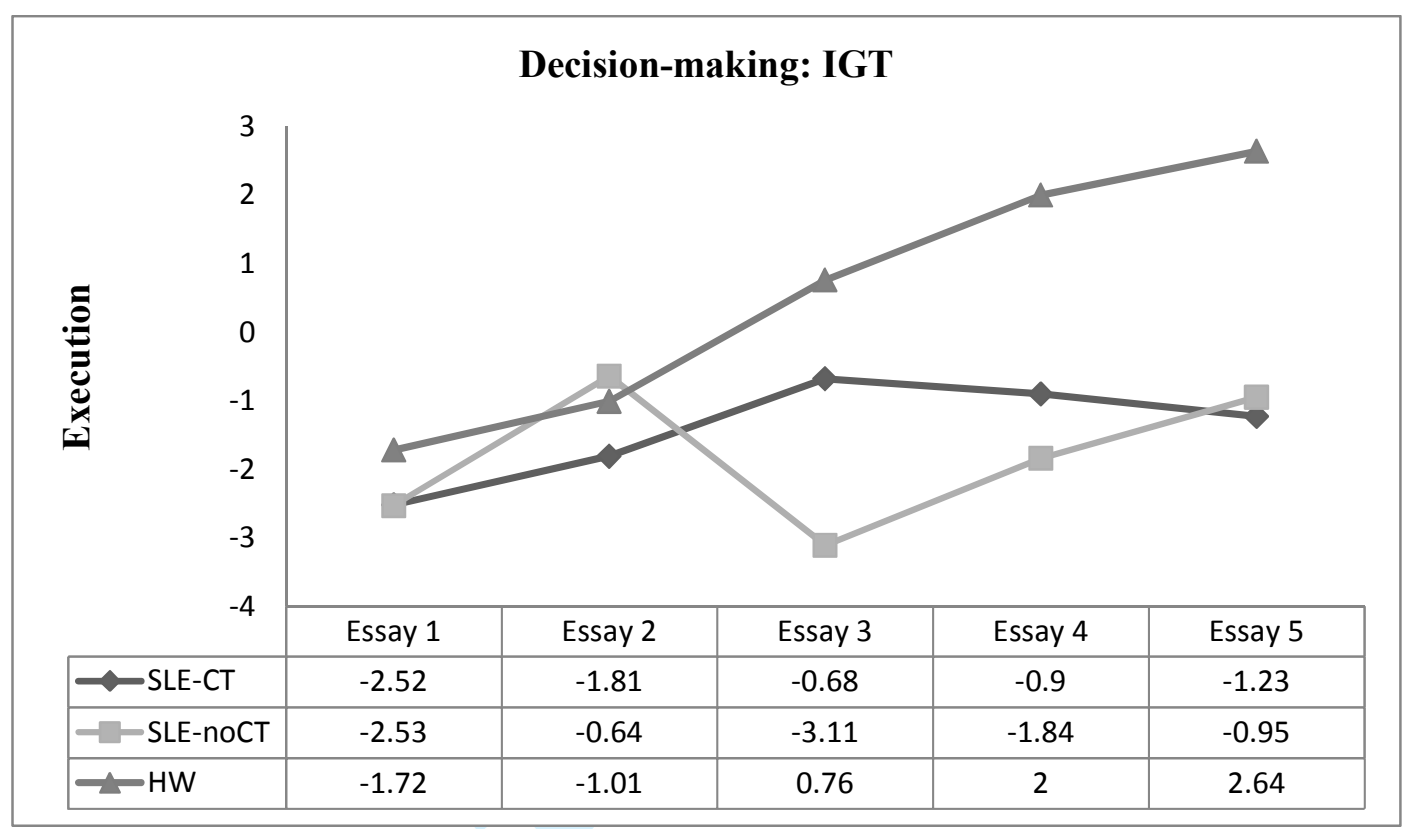

Figure 2 Decision-making in healthy women, SLE-noCT and SLE-CT 


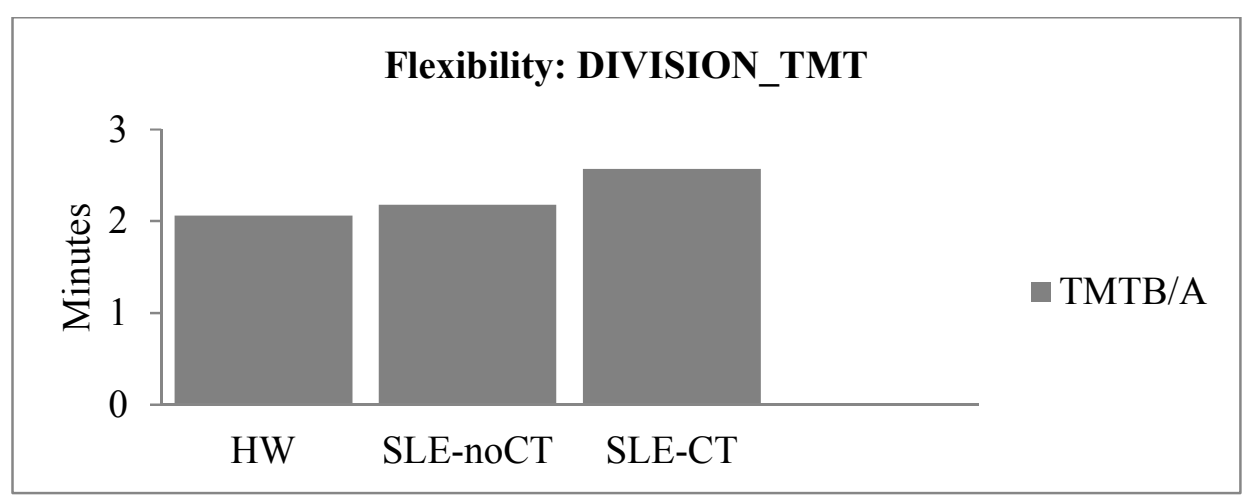

Figure 3 Cognitive flexibility in healthy women, and LES SIN and SLE-CT 